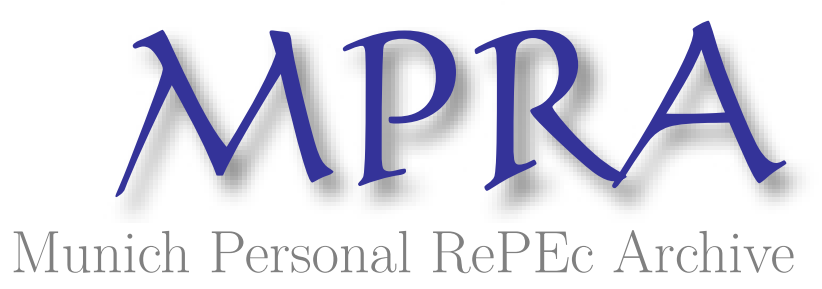

\title{
Model projections and policy reviews for energy saving in China's service sector
}

Zhang, Lin

Center of Economic Research at ETH Zurich, Switzerland

2013

Online at https://mpra.ub.uni-muenchen.de/47061/

MPRA Paper No. 47061, posted 17 May 2013 17:54 UTC 


\title{
Model projections and policy reviews for energy saving in China's service sector
}

\author{
Lin Zhang* \\ Center of Economic Research at ETH Zurich, Switzerland
}

\begin{abstract}
Energy efficiency of buildings in the service sector is becoming increasingly important in China due to the structural shift of the economy from industry to services. This paper employs a bottom-up cohort model to simulate current energy saving policies and to make projections for future energy use and $\mathrm{CO} 2$ emissions for the period 2000-2030 in the Chinese service sector. The analysis shows that energy demand in the service sector will approximately triple in 2030, far beyond the target of quadrupling GDP while only doubling energy use. However, it is feasible to achieve the target of emission reduction by $40 \%$ in 2020 even under the poor state of compliance rate of building standard. This paper also highlights four crucial aspects of designing optimal energy saving policies for China's service sector based on the model results.
\end{abstract}

Keywords: Energy saving policy; Bottom-up; Service sector

\section{Introduction}

China as the largest and fastest growing non-OECD economy consumed $18 \%$ of world energy in 2009 (IEA, 2010). The service sector accounts for 7\% of China's total energy

${ }^{*}$ CER-ETH Center of Economic Research at ETH Zurich, ZUE F9, CH-8092 Zurich, Switzerland. Tel.: +41 44 6324878; fax: +41446321362; e-mail: linzhang@ethz.ch. 
consumption. From the data reported in the China Statistical Yearbook (2010) and the China Energy Statistical Yearbook (2010), its primary energy use increased from 89 million tonnes of coal equivalent (Mtce) in 2000 to 150 Mtce in 2006. With an average growth rate of more than $10 \%$, energy use in the service sector expands much faster than the energy consumption on the aggregate level which grows at annual rate of $6.4 \%$.

Due to a high dependence on coal, China emitted 8.33 billion tonnes CO2 in 2010, accounting for a quarter of global emissions (BP, 2011). Moreover, total CO2 emissions in China increased by more than a factor of four in the past 30 years due to rapidly growing energy demand. In the same period, $\mathrm{CO} 2$ emissions in the service sector grew even faster, reaching a rate of $7.2 \%$ per year, which is almost $38 \%$ larger than the aggregate emission growth rate.

Moreover, the structural change of China's economy makes it appealing to explicitly examine service energy use not only for stabilizing future energy demand but also for cutting emissions. The service sector is the dominant economic sector in developed countries, and its importance is rising greatly in China. In 2006, the service sector contributed $40 \%$ of the GDP in China, lower than many other countries. The United States has $76 \%$ of GDP coming from the service sector in 2003 (World Bank, 2006). Lin et al.(2008) predicted that China's energy intensity would drop by $31 \%$ if the contribution of the service sector to GDP reached the levels of US. Hirschhausen and Andres (2000) predicted that the structural change of China's economy would lower the electricity demand by 10\%. The central government of China recently has announced a strategy to accelerate the development of the service sector in the next decade. Hence the service sector will contribute substantially to energy reduction in the future if treated properly.

China has set a standard of $50 \%$ reduction of energy consumption compared to buildings built in the 1980s (Standard-2005). By employing a bottom-up cohort simulation model - the SERVE-China model, this paper provides a sectoral analysis of energy use and emission trends when the Standard-2005 is implemented in China. It contributes to a better understanding of future trends and underlying factors influencing energy and emission intensity. Since most of the activities in the service sector take place in buildings, the 
model calculates the energy consumptions from the perspective of building energy use.

Several papers have studied the significance of the impacts of the service sector on energy consumption and emission reduction. Rosenblum et al. (2000) investigated the case of US; Alcantara and Padilla (2009) provided analysis for Spain, Catenazzi (2009) for Switzerland. For the case of China, Cai et al. (2009) summarized the situation and challenges of building energy consumption in general. More than $20 \%$ of the total national energy consumption comes from building energy consumptions. Low efficiency and huge energy waste of public buildings offer large potential for future energy consumption reduction. Zhou and Lin (2007) explored the reality and future trends of commercial building energy consumption. Also, some studies discussed barriers to energy efficiency in policies towards buildings (IPCC, 2007; Yao et al., 2005). Zhou et al. (2009) highlighted the difficulties of implementation of the building codes in small provincial cities.

This paper differs from above contributions in several aspects. First, most of the papers restrict their attention to the technology level. This study incorporates the economic indicators - GDP growth and energy price - to reflect the future energy consumption from macroeconomic level. Second, existing studies only discuss the barriers for energy saving policies. Information on poor implementation of energy saving policies is integrated into model parameters to illustrate the real impacts of low compliance rate. Finally, this paper synthesizes the Standard-2005 with the government targets, providing a concrete evidence of the weakness of current energy saving policies.

I find that the standard can reduce heating use by $32 \%$ and electricity consumption by $8 \%$. This analysis also shows that economic growth contributes largely to the energy consumption. High GDP growth will leads to $17 \%$ more heating use and $29 \%$ electricity consumption compared to the reference growth. I assess the possibilities of achieving two energy and emission targets announced by the government - (i) quadrupling GDP while only doubling energy use between 2000 and 2020, and (ii) emission reduction by $40 \%$ to $45 \%$ in 2020 compared with 2005 level. With current building and energy efficiency standards, target (i) cannot be achieved while target (ii) is feasible. This paper finally highlights four aspects which are crucial for policy makers on designing an optimal energy 
efficiency policy.

The rest of the paper is organized as follows. Section 2 introduces the SERVE-China model. Section 3 describes policy scenarios and the dynamics of key variables. Section 4 presents the simulation results and the assessment of government targets. Section 5 comments current energy saving policies in China based on the model simulation results, and identifies several crucial factors to be considered in policy design. Section 6 concludes the paper.

\section{The model}

The SERVE model, developed by the Center of Energy Policy and Economics is a bottomup cohort-based model which is used to simulate energy consumption in the service sector. It is a technology-based simulation model, in which the calculation of energy consumption is modeled as a complex dynamic aggregation of data. "Cohort-based" means energy use changes with the construction year and/or retrofitting year. Detailed description of the original model can be found in Aebischer 1996, Aebischer and Catenazzi 2007, Catenazzi 2009 .

The service sector refers to the production of services rather than tangible goods. Examples of specific service sectors include hotel, retail, banking, health, education, etc. The model takes the existing trends as a base line to model future energy use. To make prediction as precise as possible, many factors have been taken into consideration. Technological factors such as diffusion of technologies, improvement of efficiency, together with macroeconomic factors contribute to the dynamics of main variables described in the model equations.

In this paper, I use a modified version of the SERVE model (SERVE-China) to simulate the service energy use in China. The model version is rich in bottom-up, technological details and covers all sub-sectors of China's service sector.

Energy use in China differs significantly across regions. For simplicity, the whole country is divided into three regions: North, Central, and South. Within each region, the service sector is disaggregated into five subsectors. A subsectoral breakout includes hotel, 
retail, office, school, and others. For each of the subsectors, total energy use consists of two parts: energy use in heating and energy use in electricity. They are further broken out by end use or technologies. The heating use is based on the existing heating technologies. Seven technologies are included: CHP (combined heat and power), boilers with gas, boilers with coal, district heat with gas, district heat with coal, electric heating, and heat pumps. The electricity consumption is calculated based on the final consumption of different uses, namely electricity for cooling purpose, lighting, work related equipment, elevators and other supplementary uses. Total energy use in the service sector is the aggregation of the two parts.

The intra-structural changes within the service sector are modeled by different growth rates of value added GDP and the change of market shares in total services. The substitution among different technologies is projected by exogenous predefined substituting behaviors under different policies.

Energy use (final energy) in heating in period $t$ includes heating in the North region and Central region, which can be calculated by the equation below. The south region is not heated due to relatively high average temperature. Energy use for hot water in the three regions is also included in the final heating use.

$$
E_{t}^{\text {heating }}=\sum_{b} \sum_{i} E_{t, b, i}^{\text {heating }}=\sum_{b} \sum_{i} \sum_{r} \frac{h_{t, b, r}}{\eta_{t, b, i}}\left(A_{t, b, r} \cdot P_{t, i}\right)
$$

- $b$ : construction year of building or technology

- $i$ : technology used for heating

- $r$ : regions in the model

- $h_{t, b, r}$ : average unit energy consumption (useful energy) for sub-sector $r$ constructed in year $b$ at time $t$, the unit is $\mathrm{kWh} / \mathrm{m}^{2}$, including heating and hot water

- $\eta_{t, b, i}$ : overall efficiency of technology i installed in year $b$ at time $t$, including efficiency for heating production, conversion and end use

- $A_{t, b, r}$ : floor area for heating in sub-sector $r$ constructed in year $b$ at time $t$ 
- $P_{t, i}$ : share of fuel and heating technology $i$ on total heating supply at time $t$

- $E_{t}^{\text {heating }}$ : total energy use for heating at time $t$

Electricity use in service buildings is similar to the heating part. The only difference is that electricity use varies substantially within sub-sectors. To make projections more precise, the model differentiates buildings of the same sub-sectors into three classes: low electricity use class, median electricity use class, and high electricity use class.

$$
E_{t}^{e l e c}=\sum_{b} \sum_{g r}\left(A_{t, b, g r} \cdot h_{t, b, g r}\right)
$$

- $b$ : cohort, the construction year of the buildings

- $g r$ : electricity classes of buildings in sub-sectors (regions) of the model

- $r$ : regions of the model

- $A_{t, b, g r}$ : the floor area of buildings in electricity classes $(g r)$ constructed in year $b$ at time $t$

- $h_{t, b, g r}$ : unit energy use for electricity of buildings constructed in year $b$ at time $t$, differentiated by electricity classes $g r$

- $E_{t}^{\text {elec}}$ : final energy use for electricity at time $t$

In summary, variable $A$ is a function of the rates of construction growth, of retrofitting, and of economic growth; $h$ is a combined result of the retrofitting rate, technological progress, regional energy policies, cost functions, and it also depends on how the policies are implemented, the qualities of materials and other environmental factors. Each of the three key variables "floor area" $(A)$, "unit energy use" $(h)$, "efficiency" $(\eta)$ included in equation (1) and (2) is the function of many different exogenous parameters dynamics. This is discussed in the next section. 


\section{Policy scenarios and dynamics of key variables}

\subsection{Policy definition}

The scenarios are designed to simulate how the energy consumption varies under different building standards. The business as usual (BAU) scenario presents the situation without building codes for energy saving. This is the high end of the range of future energy use predictions. The Evolution (EVO) scenario describes the developments and dynamics when the building standard of $50 \%$ reduction of energy use is enacted. Finally, the strong policy (SP) scenario replicates the best possible outcome for energy saving which can be achieved if $65 \%$ energy saving standard is implemented.

Basically, these building energy saving standards are compulsory. It is supervised by a command and control system to enforce the compliance rate. However research shows that the mismatch between design and construction is large, which affects the final energy saving (Cai et al. 2009). This feature is captured in the model in order to reflect the reliable effect of building standards.

\subsection{Dynamics of unit energy use}

\subsubsection{Unit energy use for electricity}

The unit energy use for electricity is calculated at the electricity class level. For new buildings, it is estimated based on the reference value, the standard value of unit energy use, and the share of buildings fulfilling the building energy saving standard. It is also affected by the technical progress, intra-sectoral structural change, and other policy related improvements. It is calculated as follows:

$$
h_{t, b=t, g r}=h_{r e f, g r} \cdot(1-S(t))+h_{\text {standard }, t, g r} \cdot S(t),
$$

where $b=t$ means the building is newly constructed.

Both $h_{r e f, g r}$ and $S(t)$ are exogenous parameters. Reference values for buildings unit energy use in electricity are given in Table 1. The share of buildings achieving the target 
Table 1: Reference value for unit energy use in electricity of new buildings (Unit: $\mathrm{kWh} / \mathrm{m}^{2}$ )

\begin{tabular}{|l|c|c|c|c|c|}
\hline & Office & Hotel & Retail & Schools & Others \\
\hline Low & 30 & 30 & 40 & 30 & 40 \\
\hline Mediate & 60 & 60 & 80 & 60 & 60 \\
\hline High & 150 & 180 & 180 & 150 & 120 \\
\hline
\end{tabular}

Table 2: Share $S(t)$ of new buildings meets target value in different scenarios

\begin{tabular}{|c|c|c|c|}
\hline & BAU & EVO & SP \\
\hline before 1999 & $0 \%$ & $0 \%$ & $0 \%$ \\
\hline 2000 & $0 \%$ & $0 \%$ & $0 \%$ \\
\hline 2005 & $10 \%$ & $10 \%$ & $10 \%$ \\
\hline 2010 & $20 \%$ & $20 \%$ & $25 \%$ \\
\hline 2015 & $20 \%$ & $30 \%$ & $40 \%$ \\
\hline 2020 & $20 \%$ & $40 \%$ & $55 \%$ \\
\hline 2025 & $20 \%$ & $50 \%$ & $70 \%$ \\
\hline 2030 & $20 \%$ & $60 \%$ & $85 \%$ \\
\hline
\end{tabular}

value $S(t)$ is given in Table 2 .

The Ministry of housing and urban-rural construction reported that $7 \%$ of the total floor area reached the energy saving standard-2005 in the year 2006, 11.7\% in the year 2007, $16.1 \%$ in the year 2008, and $21.7 \%$ in the year 2009. Since the public building standard was issued later than the residential building standard, the share of public buildings that achieved the energy saving standard is lower than the current national level. The projection on the evolution of the shares $S(t)$ in different scenarios is described in Table 2.

$h_{\text {standard,t,gr }}$ (Table 3 ) is the standard value for unit energy use in electricity derived from the Standard-2005. Since the Standard-2005 is a nationwide code, the value is the same for different regions. Over time, the standard value decreases due to technical progress or other improvements. This is discussed later.

From above we can see that unit energy use in electricity for new buildings is a function of the reference value, the standard value and the share of buildings meeting the target. The evolution of unit energy use for electricity over time can be obtained by calculation. Figure 1 shows the unit energy use of new office buildings for electricity. For all of the three building classes, energy use decreases over time due to the improvement of technologies. 
Table 3: Standard value for unit energy use in electricity of building types (EVO scenario). Unit: kWh $/ \mathrm{m}^{2}$. Source: author's estimations based on Standard-2005 (GB 50189-2005)

\begin{tabular}{|c|c|c|c|c|c|}
\hline & Offices & Hotels & Retail & Schools & Others \\
\hline Low & 20 & 20 & 20 & 20 & 20 \\
\hline Median & 50 & 50 & 60 & 50 & 50 \\
\hline High & 90 & 90 & 90 & 90 & 90 \\
\hline
\end{tabular}

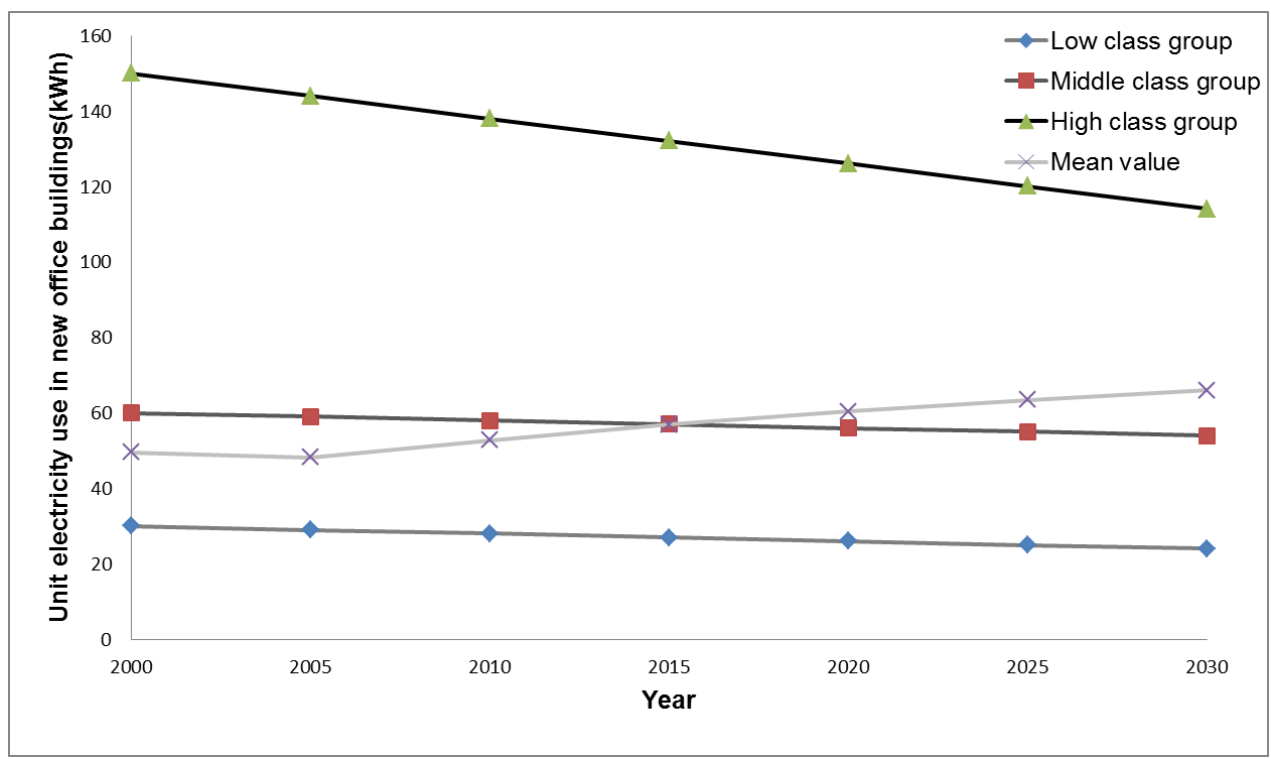

Figure 1: Unit energy use in electricity of new office buildings in EVO scenario.

However, the mean value for office buildings tends to grow over time due to the fast expansion of high class buildings. Similar observations are obtained for other building uses.

The unit energy use for electricity after retrofitting is calculated in a simple way a weighted average of the new and original building unit energy use - which is given in the following formula. This is because retrofitting buildings in electricity means simply replacing the old electric equipment with new equipment.

$$
h_{t, b, g r}=(1-p(t)) \cdot h_{t=b, b, g r}+p(t) \cdot h_{t, b=t, g r},
$$

where parameter $p(t)$ describes how many of the old equipments will be replaced. It is assumed to be $50 \%$ in the EVO scenario and $75 \%$ in the SP scenario. It can not be $100 \%$ because some appliances depend on the building structure. Lighting for instance depends 
on windows and height of offices.

\subsubsection{Unit energy use for heating}

The unit energy use for heating $\left(h_{t, b, r(g r)}\right)$ in different regions changes over time because of several reasons. Building shell improvements will allow consumers to reach higher levels of comfort with the same level of energy consumption. Heat loss currently is about 3 times as high as in similar buildings in Canada or Japan (Zhou and Lin, 2007). The advancement in construction materials and technologies will help to bring down the energy use.

The unit energy use for heating is calculated based on the status of the buildings (the construction year, and renovation year). Due to the compliance to the Standard-2005, the unit energy use in heating declines gradually for new buildings. The average unit energy use for heating of new buildings is calculated according to:

$$
h_{t, b=t, r}=h_{r e f, r} \times(1-S(t))+h_{\text {standard }, t, r} \times S(t),
$$

where $h_{r e f, r}$ is the reference value for unit heating energy use, $h_{\text {standard,t,r }}$ is the standard value at the time of construction $t$.

The operating hours of the heating systems are pre-defined to be 1500 hours because for most of the heating systems the official heating period is pre-determined by authority. Based on these facts and the assumptions, the dynamic results of unit energy consumption under different policies are summarized in Table 4.

The unit heating use for retrofit buildings is given by:

$$
h_{t, b, r}=h_{t=b, b, r} \times(1-T P(t)) \times\left(1-I P_{t, b, r}\right),
$$

where $T P(t)$ is the technological progress which will be described later. $I P_{t, b, r}$ indicates the improvement due to retrofitting. For simplicity it is defined to be $0.5 \%$ for BAU, $1 \%$ for $\mathrm{EVO}$, and $1.5 \%$ for SP. 
Table 4: Unit energy use for heating in new buildings in EVO and SP policy scenarios over time. Source: THUBERC, 2009

\begin{tabular}{|c|c|c|}
\hline & EVO $\left(\mathrm{W} / \mathrm{m}^{2}\right)$ & $\mathrm{SP}\left(\mathrm{W} / \mathrm{m}^{2}\right)$ \\
\hline $1980-1990$ & 120 & 120 \\
\hline 2000 & 63 & 63 \\
\hline 2005 & 60 & 58 \\
\hline 2010 & 55 & 52 \\
\hline 2015 & 50 & 46 \\
\hline 2020 & 45 & 40 \\
\hline 2025 & 40 & 34 \\
\hline 2030 & 35 & 28 \\
\hline 2035 & 30 & 22 \\
\hline
\end{tabular}

\subsection{Dynamics of technology}

\subsubsection{Technology efficiency}

Chinese government plans to improve efficiency through stringent standards, incentives and subsidies as well as moderate measures to accelerate the adoption of highly efficient technologies (RNECSPC, 2005). In the SERVE-China model, energy efficiency is modeled as a combination of technical efficiency and market shares of different types of technologies. The fuel/technology mix includes seven options used for heating as described before.

Technical efficiency of specific technologies will be improved by the advancement of scientific knowledge over time. Different policies have no or negligible impact on it. Hence they are assumed to be the same for EVO and SP scenarios. Reasonable values are chosen to reflect the change over time. However, if the market share of technologies changes with policies, the overall efficiency will differ across scenarios.

Table 5: Efficiency of technologies $(\eta)$

\begin{tabular}{|c|c|c|c|c|c|c|c|}
\hline Year & CHP & Boil gas & Boil coal & District gas & District coal & Electric heat & Heat pump \\
\hline 2005 & $40 \%$ & $75 \%$ & $70 \%$ & $80 \%$ & $65 \%$ & $95 \%$ & $220 \%$ \\
\hline 2030 & $65 \%$ & $90 \%$ & $90 \%$ & $95 \%$ & $90 \%$ & $99 \%$ & $450 \%$ \\
\hline
\end{tabular}

Table 6 shows the market share of heating technologies in different scenarios $\left(P_{t, i}\right)$. BAU describes the current situation of technology uses, it assumes to be the same in 2030 for BAU. CHP accounts for a third of the heat supply in the service sector now and is 
increasing due to enhanced government promotion. To evaluate the effects of building standards on energy use, the share of technologies in EVO and SP is defined to be the same, however deviating from the BAU according to China's government incentives.

Other studies show different market structure of heating technologies. Zhou et al. (2007) indicated that district heat with gas will contribute to almost half of the heat supply in 2020. Holding others the same as described in EVO, an additional scenario (LBNL) is designed to check how the market share of technologies change the model results in EVO.

Table 6: Market share of heating technologies in 2030 under different scenarios

\begin{tabular}{|c|c|c|c|c|c|c|c|}
\hline Scenarios & CHP & Boil gas & Boil coal & District gas & District coal & Electric heat & Heat pump \\
\hline BAU & $35 \%$ & $7 \%$ & $28 \%$ & $1 \%$ & $25 \%$ & $2 \%$ & $2 \%$ \\
\hline EVO/SP & $45 \%$ & $4.5 \%$ & $18 \%$ & $1 \%$ & $15 \%$ & $4.5 \%$ & $12 \%$ \\
\hline LBNL & $20 \%$ & $1 \%$ & $5 \%$ & $41 \%$ & $15 \%$ & $6 \%$ & $12 \%$ \\
\hline
\end{tabular}

\subsubsection{Technology progress}

Total Factor Productivity (TFP) is often seen as the real driver of growth within an economy. In the case of China, more than $3 \%$ of the GDP growth comes from TFP growth in the period of 1980-2000. It can also be observed that the contribution of TFP growth to GDP growth is larger for higher levels of GDP growth.

The technological progress index $(T P(t))$ is introduced to capture this feature in the model. TP $(t)$ is defined as $1 \%$ in the reference GDP growth. This is the general effect of technology from the perspective of the whole society. It will also contribute to the decrease in unit energy use for heating and electricity.

$$
h_{\text {standard }, t, r(g r)}=h_{\text {standard }, t-1, r(g r)} \cdot(1-T P(t)),
$$

In the SP scenario, further improvement $\left(T P_{g r}\right)$ can be achieved in the electricity classes level.

$$
h_{\text {standard }, t, g r}=h_{\text {standard }, t-1, g r} \cdot(1-T P(t)) \cdot\left(1-T P_{g r}(t, g r)\right),
$$


Furthermore, technologies are substitutable over time. The substitution effect is formulated in two aspects: the market share of technologies in newly constructed buildings changes over time with the improvement of technology and with the enactment of new polices, and how much of one technology in old buildings is replaced by another technology.

\subsection{Dynamics of floor area}

\subsubsection{Floor area under reference GDP growth}

Historically, there is only slight increase in total floor area before the year 2000. However, a clear and steady increase followed afterward, with an average growth rate of nearly $10 \%$. For accuracy, the growth rate of floor space is calculated in the provincial level to make a prediction on how the trend continues. The linear correlation between value added GDP and floor space in both IEA countries and in China (IEA, 2004; MGI, 2007; Zhou and Lin, 2006) helps to project future floor area increase.

The reference GDP growth rate derived from IEA (2007a) provides a baseline for the analysis. It says the GDP growth in the first decade of 21 st century is about $9.9 \%$, and followed by $6.0 \%$ and $4.8 \%$ on average in the next two decades. Value added growth rates in the service sector presented in Table 7 are derived from the reference aggregate GDP growth. Due to structural change between sectors and the increasing share of service GDP, the service GDP growth can be higher than at the aggregate level. Compared to the year 2000, value added increases by a factor of 4 until 2020 and by a factor of 7 until 2030 .

Table 7: Service sector Value added on reference GDP growth rate. Source: CYS (NBS, 2009), and by author assumptions.

\begin{tabular}{|c|c|c|c|c|c|c|}
\hline Year & Retail & Hotel & School & Office & Others & Total \\
\hline 1980 & 19.7 & 4.8 & 7.6 & 21.7 & 46.1 & 100 \\
\hline 1990 & 68.3 & 16.2 & 54.7 & 62.8 & 114.8 & 317 \\
\hline 2000 & 176.3 & 46.4 & 88.3 & 133.1 & 392.4 & 956 \\
\hline 2010 & 433.9 & 121.5 & 260.4 & 358.0 & 995.8 & 2170 \\
\hline 2020 & 777.1 & 217.6 & 466.2 & 641.1 & 1783.4 & 3885 \\
\hline 2030 & 1241.9 & 347.7 & 745.1 & 1024.6 & 2850.1 & 6209 \\
\hline
\end{tabular}


The floor area in China's service sector increased rapidly between 1996 and 2006, with an average growth rate of $8.6 \%$. More specifically, the elasticity of service floor space with respect to value added GDP in the period of 1996-2000 was 0.44, and it increased to 0.62 in the period of 2001-2006. In the reference scenario, the elasticity is assumed to remain at 0.62 until 2010 to match the fast growth in 2007-2008. Then it decreases to 0.58 for the years after 2010: the average growth rate of service floor area is assumed to decrease to $3.5 \%$ in the period of $2010-2020$ and $2.8 \%$ in the period of $2020-2030$.

Based on the historically constant growth rates in floor area between 2000 and 2008 for different provinces, the growth rates are assumed to remain the same until 2010, followed by a clear decline in the increase of floor area between 2011 and 2015. The growth rate continues to decline later on. Based on the report from IEA, energy use in the service sector grows at $6.9 \%$ per year between 2005 and 2015, and slows down to $3.3 \%$ per year from 2015 to 2030. If unit energy use keeps constant, the decline in the growth rate of energy use implies the same decrease in the floor area. Using a factor of 0.5 in year 2015 and 0.25 in year 2030, growth rates in the periods of 2010-2030 can be calculated by interpolation.

According to the Ministry of Civil Affairs, total increase in floor area of all buildings amounts to 30 billions square meters by the year 2020, which is $70 \%$ higher than in 2010 (Asia Pulse 2006, Glicksman et al. 2006, CCICED 2008). This trend is consistent with my estimation for the year 2020 where the increase in floor area is $71 \%$ compared to 2010 .

\subsubsection{Sensitivity to GDP growth}

Since the variable floor area $A$ is highly correlated with value added GDP. A variation from reference GDP growth will result in change in total floor area, and so to final energy use. To add robustness, this sensitivity analysis is conducted by focusing on one particular exogenous parameter, the GDP growth. The high growth rate is consistent with government targets for continuous rapid growth (Jiang and $\mathrm{Hu}, 2006$ ). It presents an ambitiously high economic growth rates and technological change in the future. The

low growth rate may happen due to constraints on inputs and capacity (Blanford et al., 
2008).

Table 8: Aggregate GDP growth assumptions in China. Source: Jiang and Hu, 2006; Blanford et al.,2008.

\begin{tabular}{|c|c|c|c|}
\hline & $2000-2010$ & $2010-2020$ & $2020-2030$ \\
\hline Reference & $9.9 \%$ & $6.0 \%$ & $4.8 \%$ \\
\hline High & $9.9 \%$ & $7.5 \%$ & $6.0 \%$ \\
\hline Low & $9.9 \%$ & $4.5 \%$ & $3.6 \%$ \\
\hline
\end{tabular}

Figure 2 shows the projection of total floor areas in the service sector until the year 2030 under different GDP growth assumptions. Total floor area keeps growing over time. However, the growth rate decreases since 2010.

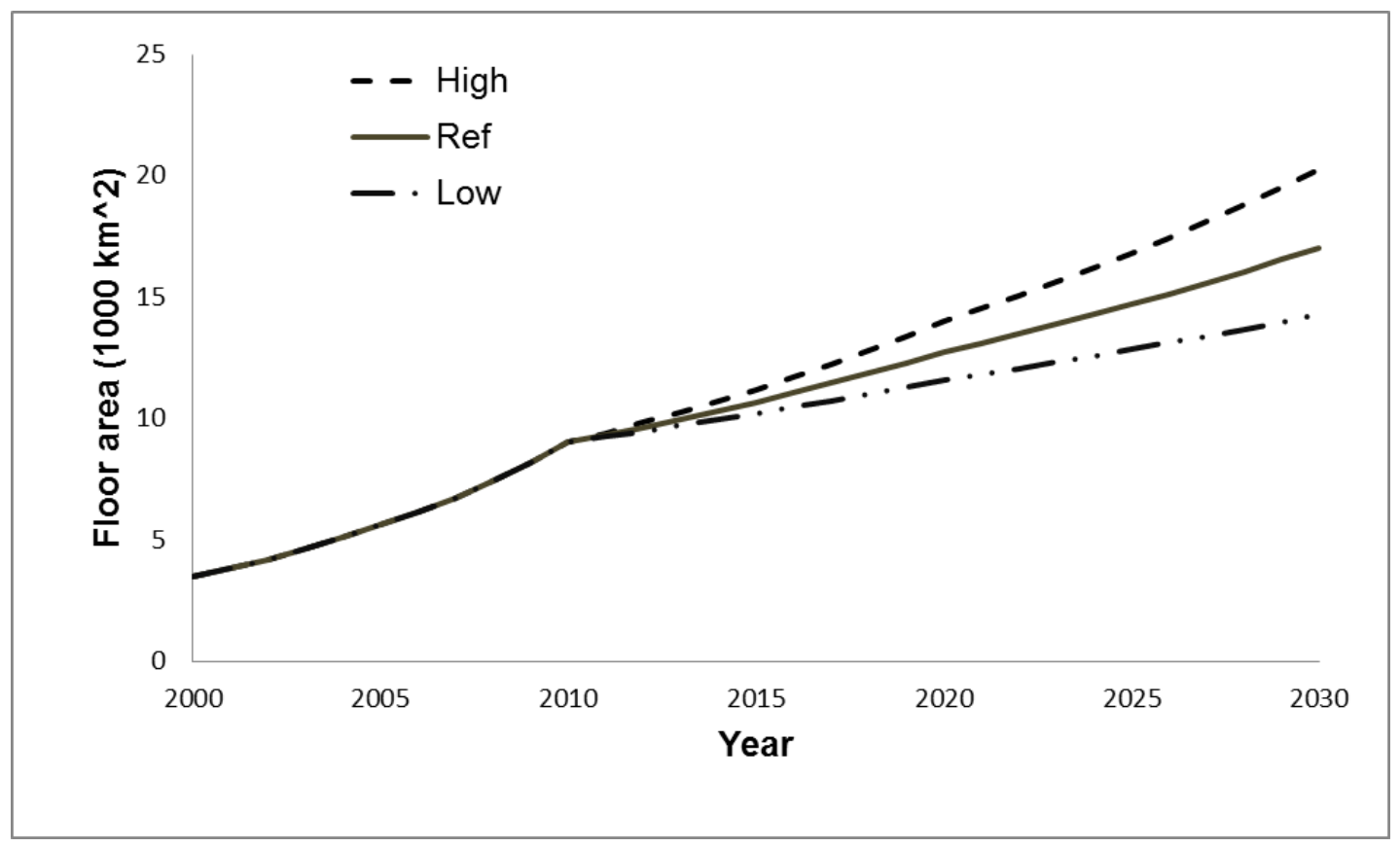

Figure 2: Estimation of total service floor area under different GDP growth patterns.

\subsection{Energy prices}

Energy prices in China used to be highly subsidized because of the centralized economic system. Coal and oil price in China have risen steadily since price decontrols began, and they are becoming more closely linked globally (Yang et al. 2012). The change in energy prices will affect unit energy use for heating $\left(h_{t, b, r}\right)$ in the model. Observation indicates that ceteris paribus, the increase in energy prices will encourage the owners to improve 
the energy efficiency of buildings, both of newly constructed and of old ones (Catenazzi 2009).

The model includes cost curves for the adjustment of unit energy use due to different energy prices. The cost curves tell how agents would improve their energy efficiency in response to higher energy prices. The shape of the cost curve described below is derived from external data sources,

$$
\text { cost_change }=a+b \cdot h_{t, b, r}+c \cdot h_{t, b, r}^{2} \text {, }
$$

The change in unit energy use for retrofitted buildings is formulated in a similar way. The change of unit electricity use due to the increase of the electricity price is included into the model using a cost curve of the following form:

$$
\text { cost_change }=a \cdot 10^{b \cdot \theta}-a,
$$

where $\theta$ is the energy saving in percent as a result of energy price changes. This implies that the change in cost for electricity use is a function of energy saving. Then we can calculate by how much unit electricity use for new buildings can be reduced if the electricity price rises.

\subsection{Summary}

To summarize, Table 9 illustrates how the scenarios and sensitivity cases discussed above are constructed in the model by changing the values of some parameters and variables.

Table 9: Abbreviation, scenarios, parameters, and variables

\begin{tabular}{|l|l|l|l|}
\hline Abbreviation & Definition & Variables & Parameters \\
\hline BAU & No building standard & baseline value & baseline value \\
\hline EVO & $50 \%$ reduction standard & $A_{\text {retrofit }}, h_{\text {standard }, t, g r}, h_{t, b, r}$ & $\eta_{t, b, i}, S, T P_{g r}, I P, p, P_{t, i}$ \\
\hline SP & $65 \%$ reduction standard & $A_{\text {retrofit }}, h_{\text {standard }, t, g r}, h_{t, b, r}$ & $\eta_{t, b, i}, S, T P_{g r}, I P, p, P_{t, i}$ \\
\hline ref & GDP reference growth & reference value for $A_{n e w}$ & $T P$ \\
\hline High & GDP high growth & high value for $A_{n e w}$ & $T P$ \\
\hline Low & GDP low growth & low value for $A_{n e w}$ & $T P$ \\
\hline
\end{tabular}


Since the growth of floor area is highly correlated with GDP growth, it is easy to derive the newly constructed floor area using this relationship. The newly constructed floor area is the same across policy scenarios (EVO, BAU, SP) if the economy grows at the same rate. However, if the economy experiences a higher GDP growth, the newly constructed floor area will also grow at a higher rate. New constructions are a major part of floor area during the simulation periods. This is why a sensitivity analysis on GDP is needed. For the existing floor area, the retrofitting rates are different according to the policies. SP has higher rate of retrofitting than EVO. So that the retrofitted floor area will differ across policies scenarios. For different GDP growth rates (reference, high, low), the retrofitting rates are assumed to be the same.

For policy related parameters such as $T P_{g r}$ and $I P$, they are set to be $0.5 \%$ in the $\mathrm{BAU}, 1 \%$ in $\mathrm{EVO}$ and $1.5 \%$ in SP. For growth related parameter $T P$, the value is $0.5 \%$, $1 \%, 1.5 \%$ in low, reference, and high GDP growth respectively.

Parameter $S$ varies between different policy scenarios (See Table 2). Change in technical efficiency $(\eta)$ is the same across scenarios (See Table 5), however, the market share of technologies $\left(P_{t, i}\right)$ changes in different policies (See Table 6). For variables such as unit energy use $(h)$, an exogenous parameter $T P$ which is adjusted according to different GDP growth rates is introduced. Hence, it changes with different GDP growth rates accordingly. (See equation $6,7,8$ )

\section{Simulation results}

\subsection{Aggregate energy use}

The BAU scenario shows the upper limit of future energy use with reference GDP growth. Results indicate that total energy consumption in the service sector will reach more than 160 Mtce in 2030, which is twice as much as in 2010. Electricity use turns out to show a similar trend as energy use as a whole in the future. It exceeds 100 Mtce which is more than half of the total energy use in the service sector. Energy use in heating looks flatter, growing relatively slowly and steadily. In 2000, electricity and heating take up half of 
total energy use each. From then on, the electricity increases at a higher growth rate, and finally one unit of heating together with two units of electricity are required to fuel one unit of GDP.

The EVO and SP scenarios show the impacts of two building standards on future energy use. However, the significance of the policy effects differs between heating and electricity (See Figure 3 and 4). Electricity use in EVO and SP scenarios decline by $7.6 \%$ and $14 \%$, respectively; while EVO and SP scenarios reduce heating demand by $32 \%$ and $37 \%$ compared with BAU, respectively.

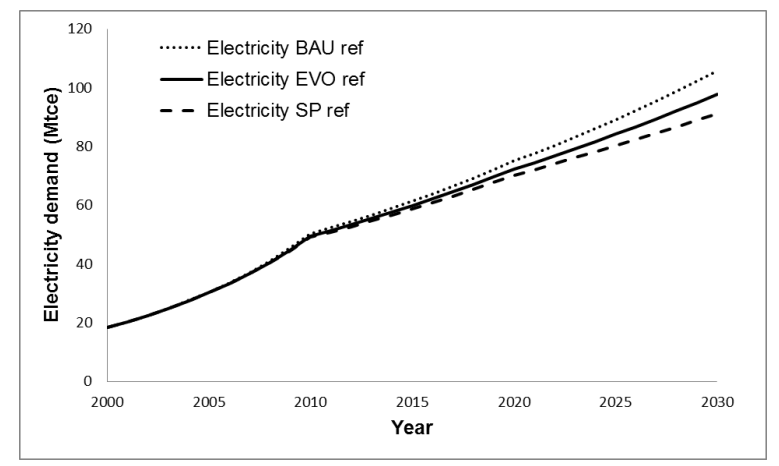

Figure 3: Electricity demand in different scenarios with reference GDP growth rate.

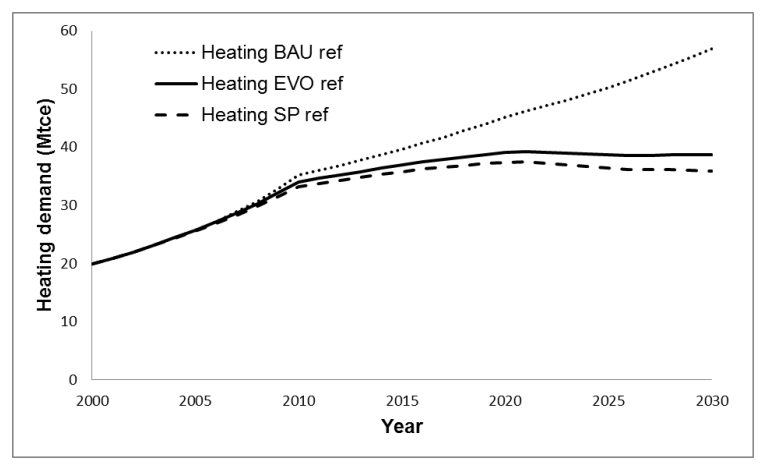

Figure 4: Heating demand in different scenarios with reference GDP growth rate.

Electricity consumption decreases from 105.8 Mtce in BAU to 97.7 Mtce in EVO and to 91 Mtce in SP at the end of the simulation period. It can be observed from Table 1 and 3 that for the low and middle electricity class the reference values are just slightly higher than the standard value, while the high class uses significantly less energy than that in the standard case. Since most of existing buildings of China belong to low and middle class because of low penetration of electric appliances at the time of construction, the standard-2005 has limited effects on energy saving in electricity consumption.

Both EVO and SP have strong effects on heating demand. Energy demand in heating reduces from 56.9 Mtce in BAU in 2030 to 38.7 Mtce in EVO, and 35.9 Mtce in SP (See Figure 4). Energy use for heating in EVO is reduced by $32 \%$ compared to BAU in 2030. Additional $5 \%$ of total energy is saved in SP.

In the EVO scenario, the sensitivity analysis on GDP suggests that high GDP growth rate will increase electricity use by $28.7 \%$ while low GDP growth rate reduces electricity 
use by $16.7 \%$ compared to the reference growth rate. Energy use for heating is also significantly affected. $17.4 \%$ higher heating use is needed in the high growth case, $11.8 \%$ lower is expected in the low growth rate compared to the reference rate.

The reference GDP growth replicates the scenario of quadrupling GDP between 2000 and 2020. Total energy use in the service sector in 2000 is about 38 Mtce, doubling energy use between 2000 and 2020 means the energy consumption in 2020 is about 76 Mtce. However, the model simulation suggests that the energy consumption will reach up to 107 and 120 Mtce, far beyond the government target.

\subsection{Sectoral energy use}

At the sectoral level, heating demand (Figure 5) is almost equally distributed among different sectors in the beginning. Retail expands its share in heating demand from $25 \%$ to $30 \%$ in the projection periods, followed by school with $2 \%$ rise. On the other hand, offices have a $2 \%$ decline; while hotels decrease the most, from $21 \%$ to $16 \%$ in the end. At the aggregated level, heating energy use in all sectors in 2020 is approximately twice of that in 2000. Heating demand after 2020 is relatively constant.

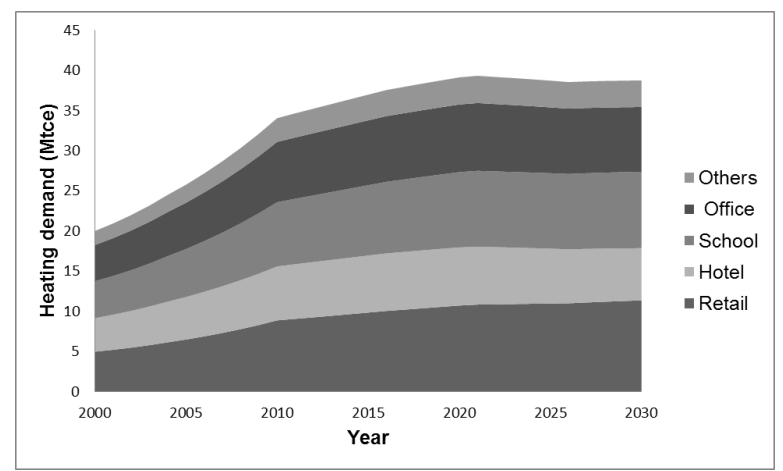

Figure 5: Sectoral heating demand in EVO-ref scenario

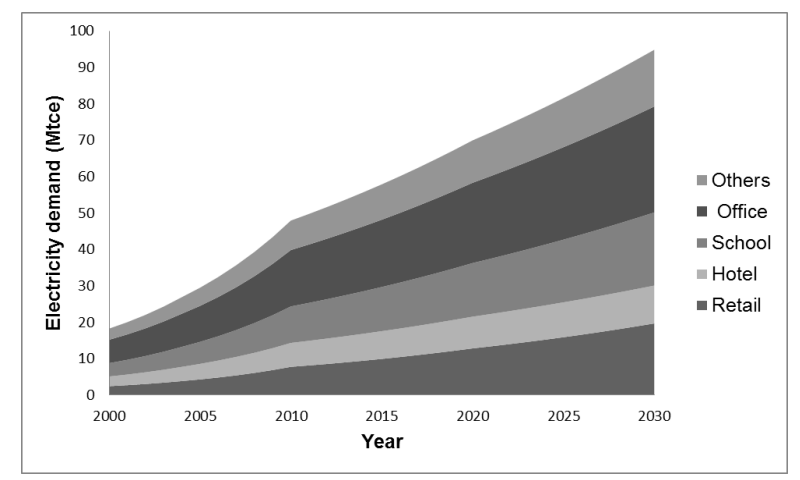

Figure 6: Sectoral electricity demand in EVOref scenario

Electricity (Figure 6) increases much faster than heating in all sectors. Retail electricity use in 2020 is 5 times higher than in 2000. In total, aggregate electricity consumption in 2020 more than triples compared to its use in 2000. The aggregate electricity demand can be higher if the economy grows at a higher rate. However, the share of electricity consumption among different end uses keeps similar as before. Only the retail sector 


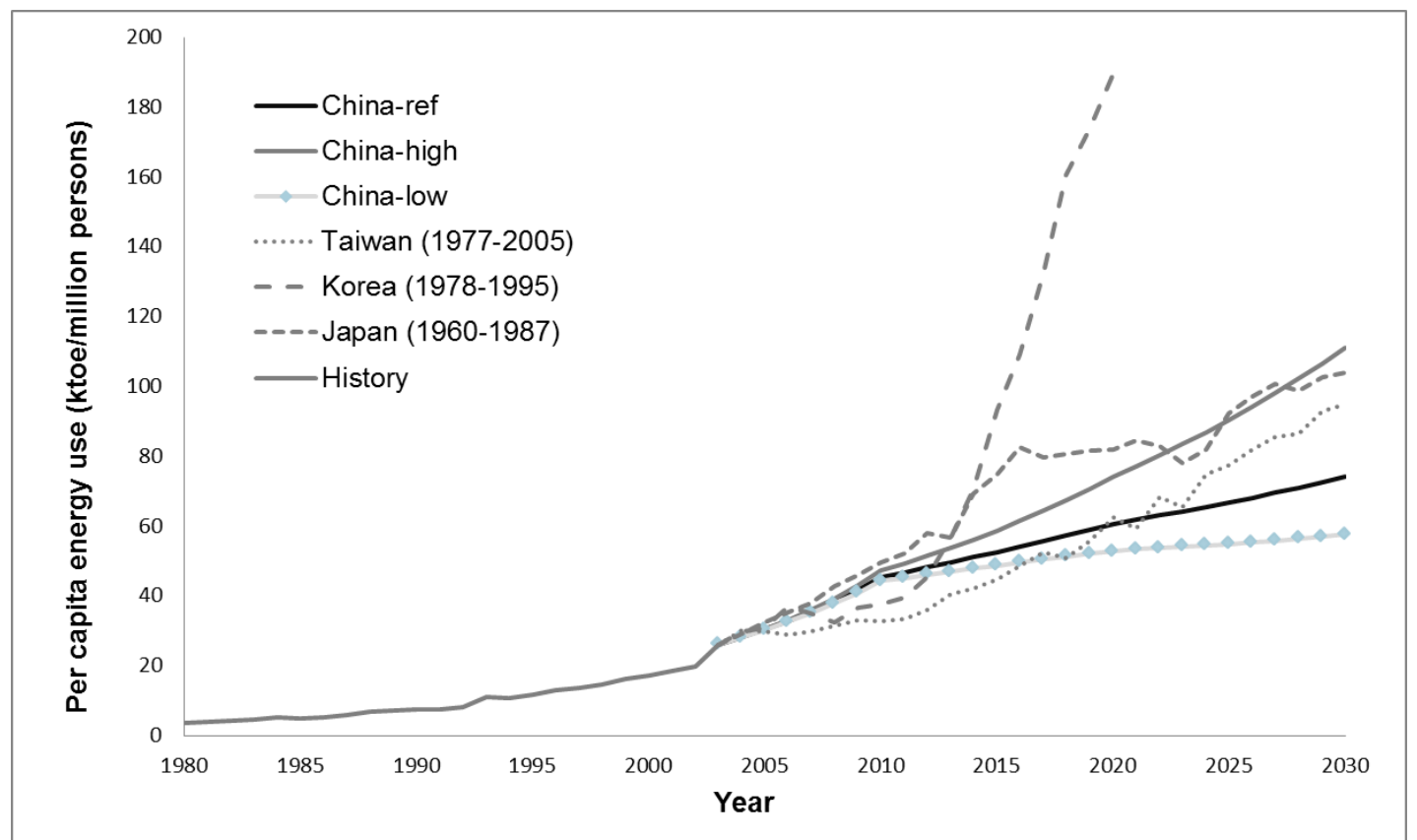

Figure 7: Per capital energy use: history, projections and international comparison. Source: IEA data(2007) and author's projections

expands its share, others keep constant or with a slight decline.

\subsection{International comparison}

To make the simulation results more illustrative, three representative economies (Taiwan, Japan, Korea) are chosen for international comparison. Lagged time series data are considered to match China's recent income level. From Penn World Table 6.1 data, per capita income in China in 2003 was roughly $\$ 4700$ (in constant 1996 dollars PPP). Japan reached this level in 1960, Korea in 1978, and Taiwan in 1977. By normalizing Japan (1960), Korea (1978), and Taiwan (1977) per capita energy use to the same level of China in 2003, the model projections are compared with historical patterns happened in these similar economies. Figure 7 shows per capita energy use in China's service sector and its neighboring economies. Per capita energy use in the service sector has risen relatively slow in China, but it is projected to follow historical patterns as energy intensity declines. 


\subsection{Emission intensity}

Figure 8 shows the CO2 emissions in EVO-ref scenario and two outliers. The upper bound of model projections is derived from the BAU-high scenario, and the lower bound comes from the SP-low scenario. We can see that the CO2 emissions are reduced significantly when certain policies are designed. The largest difference between BAU-high and SP-low reaches up to $46 \%$ in 2030. CO2 emissions are not clearly defined in IEA data (2007).

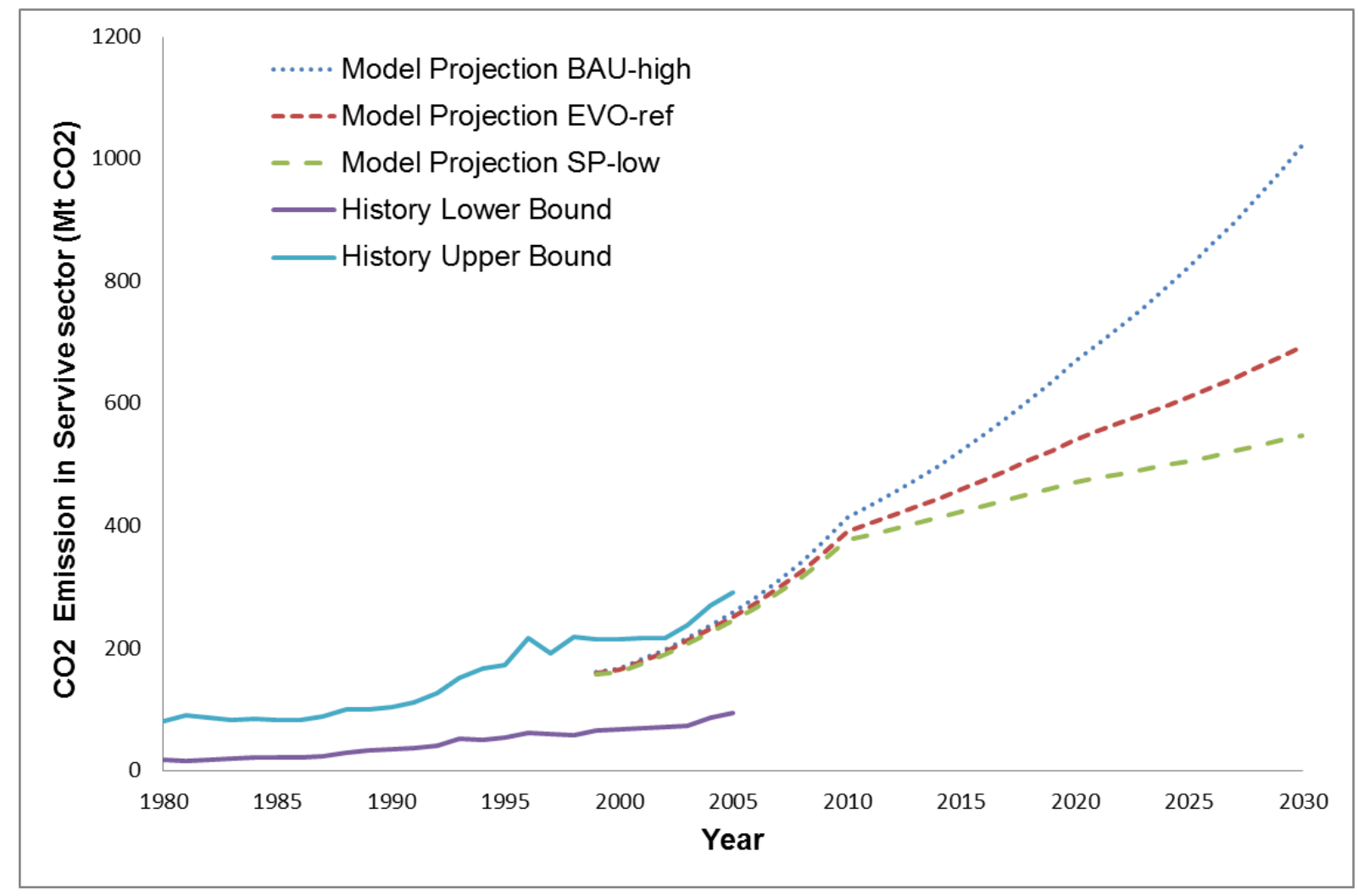

Figure 8: $\mathrm{CO} 2$ emissions (Mt CO2): history and future projections Source: IEA data(2007) and author's projections

Parts of the electricity and heat use are grouped in other sectors. To catch the real value in service CO2 emissions, a lower and an upper bound are calculated to capture the $\mathrm{CO} 2$ emission trend in history. The lower bound uses data from "commercial and public sector". Since not all of the electricity and heating use in service sector are classified in this sector, it is necessary to estimate an upper bound for the CO2 emissions. The upper bound is calculated by adding the "commercial and public sector", the "non-specific other sector", and emissions from the "auto producers" where electricity and heat are produced for own use only. The real historical $\mathrm{CO} 2$ emission in the service sector should then 
fall into the range between lower and upper bound. The first few years of the model projections fit the range well. These historical trends (both in the lower case and upper case) continues in the model projections.

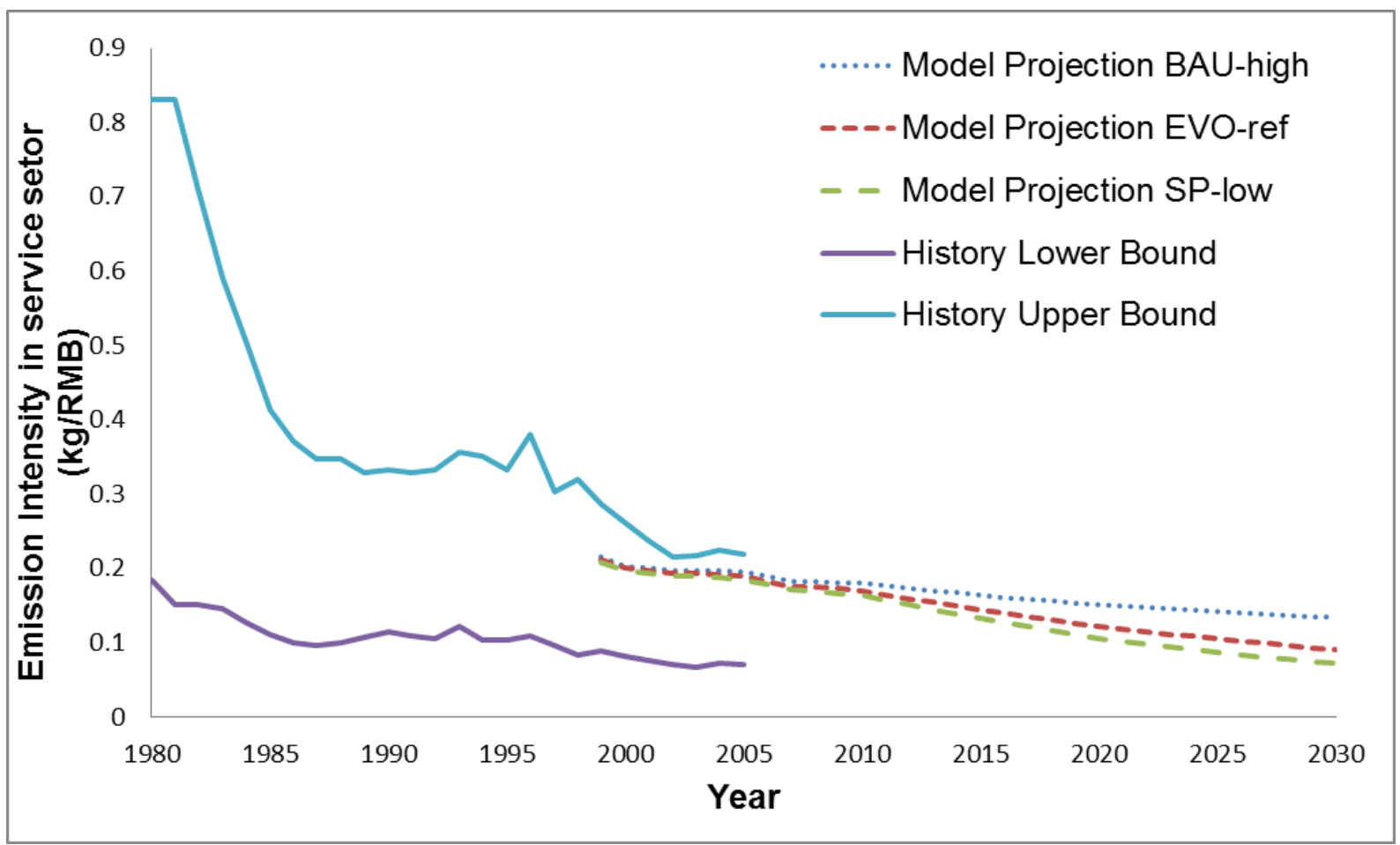

Figure 9: Emission intensity in service sector: history and future projections (Unit: $\mathrm{kg} / \mathrm{RMB}$ ). Source: IEA data(2007) and author's projections

$\mathrm{CO} 2$ emission intensity in the service sector is calculated by emissions per unit of value added. The central government announced an ambitious target of reducing CO2 emission intensity by $40 \%$ to $45 \%$ in 2020 compared with the level of 2005. From Figure 9 we can see that in the service sector the CO2 emission intensity reduction ranges from about $26 \%$ to $46 \%$ in the different scenarios in 2020 compared to 2000. In the EVO scenario, the emission intensity reduction is about $39.2 \%$, approaching the government target. Since big cities have more stringent building standard than the Standard-2005. The emission intensity target is feasible under the current situation of building energy consumption. 


\section{$5 \quad$ Policy design advice}

Based on the model simulations, together with historical and international analysis of the growth trends, I highlight four crucial aspects in designing an energy efficiency policy in the service sector in China, particularly for the achievement of the two assessed government targets .

1. New building dominance: In China the service sector is expanding rapidly with an average growth rate of $10.8 \%$ in the period 2000-2010. As from model results, the floor area will expand by three to four times based on the level of year 2000. That is, in 2030 the fraction of new buildings (built between 2010 and 2030) will take up more than 90\% of all buildings. Cheng (2010) shows that an additional one billion $\mathrm{m} 2$ of new buildings will be constructed until 2020. Higher GDP growth will lead to further increase in floor area which requires more energy. It is estimated that total energy use in high GDP growth scenario will increase $30 \%$ compared to low GDP growth according to model projection. Hence in China, unlike European countries (e.g. according to Ravetz (2008) $75 \%$ of all existing building stock in the UK will remain in use in 2050), policies on new buildings rather than building retrofitting are essential to the national energy saving plan.

2. Cooling speed up: Heating is the major energy use for comfort at the final energy consumption level in China. Heating increases more than 3 times during the projection period, and energy saving standards damp down the energy use in heating significantly. However, little has been done for cooling. When considering primary energy and CO2 emissions, cooling demand will soon become as important as heating. Cooling uses only 2.57 Mtce of total energy in 2000, but the value approaches the level of 20 Mtce in 2030, which is almost 8 times of the year 2000's value according to the projections. Yao et al. (2005) indicate the similar result of the rise in cooling intensity. Current energy saving policies have only a minor impact on saving energy use in cooling. Hence traditional building standards and subsidiary measures have to be strengthened to foster an efficient use of energy for cooling purposes.

3. Energy prices and $\mathrm{CO} 2$ taxes: Energy prices hold a weak direct impact on energy demand in the service sector. The price elasticity in China is about 0.001 in the short 


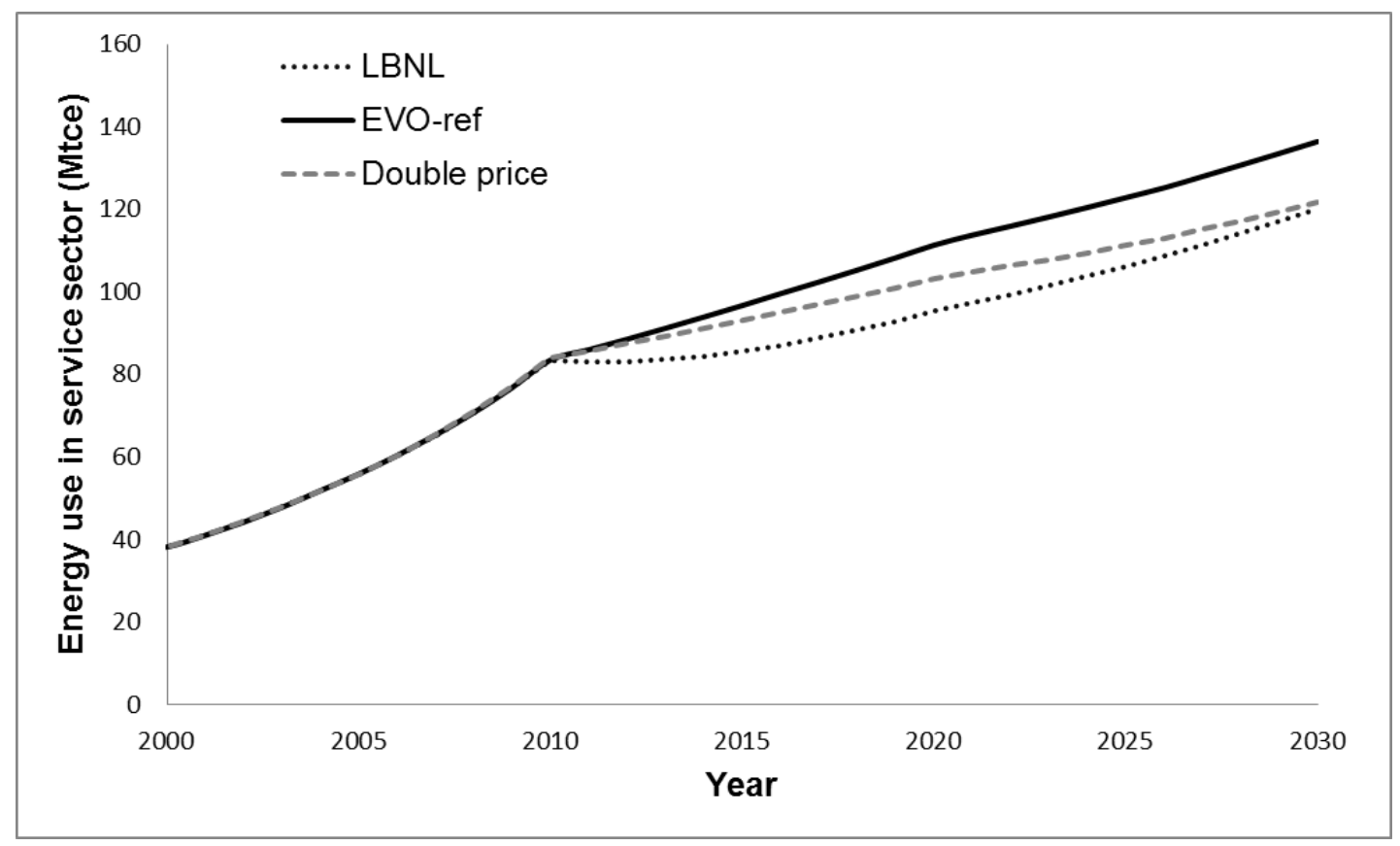

Figure 10: Projected energy use across scenarios

run and 0.005 in the long run (Cooper, 2003). As the simulation suggests, a doubling in the energy price would decrease electricity use by $8 \%$. The $\mathrm{CO} 2$ emission reduction is modest.

In China, a very large portion of the electricity production comes from fossil fuels. Recently, the central government pushes power plants to install emission control devices on one hand; on the other hand, power plants with renewable energy (mainly hydro, but also increasingly wind, solar) are under construction or planned. The enactment of the renewable energy law in China shows strong support of new energies from the government level. These strategies would decline the $\mathrm{CO} 2$ content of electricity. In this regard, CO2 taxes will induce stronger substitution in the fuel mix of heating systems and electricity generation.

The model projection also reflects the advantage of CO2 tax compared with rising energy price. From Figure 10 we see that a fuel mix revolution (LBNL scenario gives different technologies and fuel mix compared with EVO) offers a fruitful perspective for both energy saving and emission reductions. Hence, imposing CO2 tax would be an adequate policy measure to accelerate the reduction of the CO2 emissions and the energy intensity of the Chinese energy system. 
4. Enactment and implementation of policy measures: The standard-2005 includes an ambitious target of 50\% energy saving compared to pre existing buildings, and more stringent target of $65 \%$ energy saving in big cities. However, the compliance rate of buildings is relatively low (21.7\% in 2009). Higher fulfillment of target value for new buildings will further reduce energy consumptions. Nevertheless, further improvement of compliance rate needs government consideration from the perspective of education and training. As reported by IHS, China took $25 \%$ of the world construction workers, among which only about $10 \%$ have professional certification and less than $30 \%$ take part in regular training. Further energy saving can be achieved if the central government of China implements similar policies and funds the training and education of construction workers. It is estimated from the model that if $80 \%$ of the new buildings reaches the standard after construction, the total energy use in the service sector will be reduced by up to $9 \%$ in the year 2030 .

\section{Conclusion}

This paper provides a detailed view of the near term prospects for building energy saving in China's service sector. By formulating the building Standard-2005 specifically in the model, this paper captures how technology specifications affect the energy consumption and emission reduction. The capability of including the compliance rate of building codes into the model makes the results much more reliable. Three different GDP growth rates are designed to capture the macroeconomic influence on energy use. Starting with similar energy consumption in the year 2000, electricity increases 5 to 8 times depending on different scenarios, while growth of heating use is flatter than electricity. In energy use for heating, policies such as compulsory building standard show high potential energy saving: $32 \%$ of final energy can be saved under a 50\% energy saving policy (EVO); economic growth contributes $17 \%$ of the energy consumption growth. From the sensitivity analysis we can see the increase in electricity use is much more driven by economic growth, reflecting $29 \%$ of the energy use difference between baseline (reference growth) and high growth; energy saving policy (SP) reduces only $8 \%$ of future energy consumption. In 
general, the effects on the energy intensity in the service sector are encouraging: $33 \%$ of the energy intensity reduction can be achieved in 2020 and more than 50\% in the year 2030.

The model results suggest that at least $26 \%$ reduction in emission intensity can be achieved in 2020 and 34\% in 2030 (compared with the year 2000 under BAU-high scenario). With the nationwide Standard-2005, emission reduction can reach up to $39 \%$, the target of $40 \%$ to $45 \%$ reduction of emission intensity is possible since more strict building energy saving codes are implemented by large capital cities. However, even with such encouraging results, the target of quadrupling GDP while only doubling energy use from 2000 to 2020 is not possible in the service sector under the model projections.

This paper also delivers additional insight for designing better energy saving strategy for China's service sector. Energy saving policies on commercial buildings have to be further differentiated between new constructions and old ones. Cooling energy use will gain in magnitude soon as the economic development. Hence future policies should consider energy saving in cooling in a similar way as heating. Furthermore, CO2 taxes could accelerate the substitution of fuels and stimulate the technology advancement in heating and electricity generation. Also, it is worth noting that professional education and training are necessary for the improvement of the compliance rate. 


\section{References}

[1] Aebischer, B. (1996): Perspectives of the Energy Consumption in the Swiss Service Sector: Modeling and Results. Proceedings of International Conference on the Perspectives of the Energy Demand and Efficient Energy Use, POSCO Centre. Seoul, Korea.

[2] Aebischer, B., Jakob, M., Catenazzi, G. (2007). Impact of climate change on thermal comfort, heating and cooling energy demand in Europe. France. ISBN: 978-91-6330899-4.

[3] Alcantara, V. and Padilla, E. (2009). Input-output subsystems and pollution: An application to the service sector and CO2 emissions in Spain. Ecological Economics, Volume 68, Issue 3, Pages 905-914 http://dx.doi.org/10.1016/j . ecolecon. 2008. 07.010

[4] Asia Pulse (2006): China Sets Energy Efficiency Standards in Urban Construction. Asia Pulse Pte Ltd. Website article published on 26 February 2006. http://www. asiapulse.com

[5] Blanford, G. J., Richels, R. G., and Rutherford, T. F. (2008). Revised emissions growth projections for China: why post-Kyoto climate policy must look east. PostKyoto international climate policy, Cambridge.

[6] BP Statistical review of Energy, June 2011 cited in Reuters, "Global CO2 emissions rose over 10 per cent in 2010", BP, 8 June, 2011.

[7] Building Energy Reduction Center at Tsinghua University (THUBERC, 2009): Annual research report on building energy reduction in China. China Building Press, Beijing, China.

[8] Cai, W.G., Wu, Y., Zhong, Y., and Ren H.(2009): China building energy consumption: Situation, challenges and corresponding measures, Energy Policy 37(6), 2054-2059. 
[9] Catenazzi, G. (2009): Advances in techno-economic energy modeling: Costs, dynamics and hybrid aspects, Doctoral dissertation, Diss. ETH No. 18016. http://e-collection.library.ethz.ch/eserv/eth:41888/eth-41888-02.pdf

[10] Cheng, C. (2010). A new NAMA framework for dispersed energy end-use sectors. Energy Policy, 38, 10, 5614-5624.

[11] Cooper, J. (2003): Price elasticity of demand for crude oil: estimates for 23 countries. OPEC review.

[12] Design standard for energy efficiency of public buildings in China, GB 50189-2005.

[13] Energy efficiency and Urban Development, CCICED 2008 Annual General Meeting. http://www.iddri.org/Activites/Ateliers/0811_Task-Force-on-Urban-Development_ report.pdf

[14] Facilitating Deployment of Highly Efficient Combined Heat and Power Applications in China, U.S. Environmental Protection Agency Combined Heat and Power Partnership and Asia Pacific Partnership on Clean Development and Climate. http://www.epa.gov/chp/documents/chpapps_china.pdf.

[15] Glicksman, L., Norford, L., and Greden, L. (2006): SUSTAINABLE URBAN HOUSING IN CHINA, Alliance for Global Sustainability Book series, 2006, Volume 9, Part One, 8-21, DOI: 10.1007/978-1-4020-4786-2_2

[16] Hirschhausen, C. and Andres, M. (2000). Long-term electricity demand in China From quantitative to qualitative growth? Energy Policy, Vol. 28, 231-241.

[17] IEA (2004): 30 years of energy use in IEA countries. International Energy Agency, Paris, France.

[18] IEA (2007a): World Energy Statistics 2007. International Energy Agency, Paris, France.

[19] IEA (2010): World Energy Statistics 2010. International Energy Agency, Paris, France. 
[20] IPCC, 2007. Assessment of policy instruments for reducing GHG from buildings. IPCC.

[21] Jiang, K. and Hu, X. (2006): Energy demand and emissions in China: scenarios and policy options, Proceedings of the Sixth International Conference for Enhanced Building Operations, Shenzhen, China.

[22] Lin, J., Zhou, N., Levine, M., and Fridley, D. (2008): Taking out 1 billion tons of CO2: The magic of China's 11th Five-Year Plan? Energy Policy, Volume 36, Issue 3, 954-970.

[23] MGI (2007): Curbing global energy demand growth: the energy productivity opportunity. McKinsey Global Institute.

[24] National Bureau of Statistics, 2006-2010. China Statistical Yearbooks. Beijing, China.

[25] Ravetz, J. (2008). State of the stock - What do we know about existing buildings and their future prospects? Energy Policy, 36, 12, 4462-447.

[26] RNECSPC 2005. Research on National Energy Comprehensive Strategy and Policy of China, Economic Science Press, 2005.

[27] Rosenblum, J., Horvath, A., and Hendrickson, C. (2000): Environmental Implications of Service Industries. Environ. Sci. Technol., 34 (22), pp 4669-4676

[28] World Bank (2006): The World Development Indicators 2006 (WDI) Database.

[29] Yang, C., Xuan, X., and Jackson, R.(2012): China's coal price disturbances: Observations, explanations, and implications for global energy economies. Energy Policy $51,720-727$.

[30] Yao, R., Li, B., and Steemer, K. (2005): Energy policy and standard for built environment in China. Renewable Energy, 30, p. 1973-88. 
[31] Zhou, N., Levine, M.D., and Price, L. (2009): Overview of current energy efficiency policies in China. Energy Policy. doi:10.1016/j.enpol.2009.08.015.

[32] Zhou, N., and Lin, J. (2007): The reality and future scenarios of commercial building energy consumption in China. LBNL-1036E, Lawrence Berkeley National Laboratory, United States.

[33] Zhou,N., McNeil, M. A., Fridley, D., Lin, J., Price, L., Stephane de la Rue du Can, Sathaye, J., Levine, M. (2007): Energy use in China: sectoral trends and future outlook. LBNL-61904, Lawrence Berkeley National Laboratory, United States. 